\title{
Einige Bemerkungen über Farbenempfindung.
}

Von

\section{A. Eugen Fick,}

Arzt in Richmond, Kapland.

Die Untersuchung Dobrowolsky's "Ueber den Unterschied in der Farbenempfindung bei Reizung der Netzhaut an einer oder an mehreren Stellen zu gleicher Zeit" beschäftigt sich mit einer Thatsache, die zuerst von $\operatorname{mir}^{1}$ ) mitgetheilt worden ist. Man möge mir daher einige Bemerkungen uber diesen Gegenstand erlauben, obgleich mir die Dobrowolsky'sche Arbeit im Original nicht zugänglich und nur aus einem Referat ${ }^{2}$ ) bekannt geworden ist.

Wenn man einen farbigen leuchtenden Punkt aus geeigneter Entfernung betrachtet, so ist man bekanntlich nicht im Stande die Farbe desselben zu erkennen, sondern man nimmt lediglich einen leuchtenden Punkt wahr. Werden jetzt aber eine gewisse Anzabl gleicher Farbenpunkte aufgedeckt, so erkennt der Beobachter ohne Schwierigkeit die Farbe dieser Punkte. Es unterstitzen sich also getrennte Stellen unserer Netzhaut zur Erzeugung einer Farbenempfindung. Dies ist die von mir gefundene Thatsache. Dobrowolsky hat nun meinen Versuch wiederholt und variirt, um eine Erklärung der Thatsache aufzufinden. Er ist dann zu dem Resultat gekommen, dass 16 leuchtende farbige Punkte anf eine grössere Entfernung als farbig erkannt werden, wie einer, hauptsächlich wegen der dabei erscheinenden Zerstreuungskreise. Ich möchte nun darauf aufmerksam machen, dass der Versuch mit den 16 leuchtenden Farbenpunkten auch gelingt, wenn von Zer-

1) Fine Notiz über Farbenempfindung von A. Fugen Fick, dies Archiv 1878.

2) Schmidt's Jahrbiucher, Heft 9, 1885. 
streuungskreisen gar keine Rede sein kann. Allerdings war meine erste Mittheilung über diesen Gegenstand sehr kurz gehalten, jedoch nicht so kurz, dass ich vergessen hätte ausdrücklich zu bemerken: "Eine etwaige fehlerhafte Refraction des beobachtenden Auges wird durch eine passende Brille corrigirt und so dafür gesorgt, dass kleine seharfe Bilder auf Stellen der Netzhaut entstehen, die durch tief beschattete Partien von einander getrennt sind.

Es hat also Dobrowolsky nur gezeigt, dass der ursprüngliohe Versuch auch eben noch gelingt, wenn man eine von mir ausdrücklich erwähnte Vorsichtsmaassregel ausser Acht lässt; eine Erklärung geliefert zu haben, kann dagegen meines Erachtens jener Forseher nicht den mindesten Anspruch machen. Dagegen hat er die ursprüngliche Thatsache erweitert. Dobrowolsky fand nämlich, dass auch Netzhautstellen des zweiten Auges im Stande sind, dem ersten Auge beim Erkennen kleiner farbiger Objecte zu Hülfe zu kommen, was beiläufig bemerkt vielleicht der schlagendste Beweis gegen seine Erklärung des Phänomens durch Zerstreuungskreise ist.

Auch eine zweite, von mir ausdrücklich erwähnte Maassregel scheint Dobrowolsky nicht beachtet zu haben. Er sagte nämlich, dass es ihm nie gelungen sei, unter kleinerem Gesichtswinkel als 32 See. die Farbe der leuchtenden Punkte zu erkennen, während ich noch unter Gesichtswinkeln von 14, ja von 11 Sec. die leuchtenden Punkte und ihre Farbe wahrnehmen konnte. Dobrowolsky hat eben offenbar meinen Rath nicht beachtet, die leuchtenden Farbenpunkte sebr lichtstark zu machen. Wie das zu machen sei, habe ich gleichfalls in meiner „Notiz über Farbenempfindung" zwar kurz, aber jedenfalls verständlich genug mitgetheilt.

Der misslungene Erklärungsversuch Dobrow olsky veranlasst mich zu noch einer Bemerkung. Wenn ich auf eine grosse Entfernung eine einzelne Antilope nicht mehr erkenne, wohl aber eine ganze Heerde, so ist das durehaus nichts wunderbares. Denn das Netzhautbild der Antilope $A$ macht nicht etwa dasjenige der Antilope $B$ selbst deutlicher, sondern auf rein psychischem Wege mache ich mir durch Beobachtung der einzelnen, gleich undeutlichen Netzhautbilder, ihrer Stellung zueinander, ibrer Verschiebung gegeneinander klar, dass es sich nicht um eine Schaf- oder 
20 A. Eugen Fick: Finige Bemerkungen über Farbenempfindung.

Ziegenheerde, sondern um Atilopen handelt. Wenn dagegen ein einzelnes rothes Quadrat wegen zu grosser Entfernung seine Farbe nicht erkennen lässt, wohl aber eine Anzahl solcher Quadrate, die auf getrennten Stellen meiner Netzhäute ibre Bilder entwerfen, so hat in der That das Netzhautbild des Quadrates $A$ dasjenige des Quadrates $B$ deutlicher gemacht, was nichts weniger als selbstverständlich und leicht zu begreifen ist.

Uebrigens ist die gegenseitige Unterstützung von getrennten Netzhautstellen vielleicht nicht einmal wunderbarer und schwerer verständlich als gegenseitige Unterstiitzung von un mittelbar an e inander grenzenden Netzhautstellen. Es ist dies ja nur ein anderer Ausdruck für die schon seit langer Zeit bekannte Thatsache, dass ein farbiges Object unter sehr kleinem Gesichtswinkel farblos, unter grösserem farbig erscheint. Man kann sagen, hier verhilft eine sehwach gereizte Netzhautstelle $A$ der ebenso gereizten (unmittelbar angrenzenden) Netzhantstelle $B$ dazu dem Gehirn eine Farben empfindung zu vermitteln, welche bei Reizung von $B$ allein und von $A$ allein nicht zu Stande kommt.

Ich glaube, wer tiefer in dies Problem eindringen will, muss nicht nur den Versuch bezüglich der Zahl und Anordnung der leuchtenden Punkte variiren, sondern vor allem festzustellen suchen, welcher Erfolg eintritt, wenn die Hälfe der Punkte in einer, die andere Hälfte in der Complementärfarbe leuchten, oder wenn andere Farben combinirt werden. 